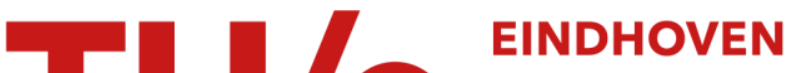

\section{Self-assembeld ge-dots : growth, characterization, ordering and applications}

Citation for published version (APA):

Schittenhelm, P., Engel, C., Findeis, F., Abstreiter, G., Darhuber, A. A., Bauer, G., Kosogov, A. O., \& Werner, P. (1998). Self-assembeld ge-dots : growth, characterization, ordering and applications. Journal of Vacuum Science and Technology, B, 16(3), 1575-15811. https://doi.org/10.1116/1.589942

DOI:

10.1116/1.589942

Document status and date:

Published: 01/01/1998

\section{Document Version:}

Publisher's PDF, also known as Version of Record (includes final page, issue and volume numbers)

\section{Please check the document version of this publication:}

- A submitted manuscript is the version of the article upon submission and before peer-review. There can be important differences between the submitted version and the official published version of record. People interested in the research are advised to contact the author for the final version of the publication, or visit the $\mathrm{DOI}$ to the publisher's website.

- The final author version and the galley proof are versions of the publication after peer review.

- The final published version features the final layout of the paper including the volume, issue and page numbers.

Link to publication

\section{General rights}

Copyright and moral rights for the publications made accessible in the public portal are retained by the authors and/or other copyright owners and it is a condition of accessing publications that users recognise and abide by the legal requirements associated with these rights.

- Users may download and print one copy of any publication from the public portal for the purpose of private study or research.

- You may not further distribute the material or use it for any profit-making activity or commercial gain

- You may freely distribute the URL identifying the publication in the public portal.

If the publication is distributed under the terms of Article 25fa of the Dutch Copyright Act, indicated by the "Taverne" license above, please follow below link for the End User Agreement:

www.tue.nl/taverne

Take down policy

If you believe that this document breaches copyright please contact us at:

openaccess@tue.nl

providing details and we will investigate your claim. 


\title{
Self-assembled Ge dots: Growth, characterization, ordering, and applications
}

\author{
P. Schittenhelm, ${ }^{\text {a) }}$ C. Engel, F. Findeis, and G. Abstreiter \\ Walter Schottky Institut, Techn. Univ. München, Am Coulombwall, 85748 Garching, Germany
}

A. A. Darhuber and G. Bauer
Institut für Halbleiterphysik, Univ. Linz, Altenbergstr. 69, 4040 Linz, Austria

A. O. Kosogov and P. Werner

Max-Planck-Institut für Mikrostrukturforschung, Weinberg 2, 06120 Halle, Germany

(Received 8 November 1997; accepted 2 March 1998)

\begin{abstract}
The Stranski-Krastanow growth mode, which leads to the self-assembled formation of dots, allows one to exceed the critical thickness without introducing dislocations. We report the coverage limits for the dislocation-free dot regime in dependence of the Ge content, and also the composition dependent thickness of the two-dimensional wetting layer. To reduce the size inhomogeneity of the self-assembled dots, we investigated ordering effects in Si/Ge-dot multilayers. The experiments do not only reveal a strong vertical ordering of the dots, but also a lateral correlation and a significantly increased size homogeneity is observed. Results on first device structures, a $n p n$-infrared detector and a silicon based tunneling structure, both with embedded layers of self-assembled Ge dots, are presented. (C) 1998 American Vacuum Society. [S0734-211X(98)09903-X]
\end{abstract}

\section{INTRODUCTION}

The strain-driven self-assembled formation of Ge nanostructures on $\mathrm{Si}$ during molecular beam epitaxy (MBE) growth in the Stranski-Krastanow mode has recently attracted a lot of interest. ${ }^{1}$ One promising aspect is the in situ formation of quasi-zero-dimensional structures without the need of sophisticated structuring technology, ${ }^{2}$ at the same time avoiding defects related to a postgrowth structuring.

The second important aspect is the possibility to avoid the critical thickness limitation of pseudomorphic SiGe heterostructures, that has turned out to be one of the most severe restrictions on the road to many proposed device applications. ${ }^{3}$ The Stranski-Krastanow growth mode, which leads to the self-assembled formation of dots in strained systems, permits to exceed the critical thickness without introducing dislocations. ${ }^{4}$ This allows for the realization of large, dislocation-free, Ge-rich dots. Following a brief description of the experimental techniques in Sec. II of this article, we present the upper and lower coverage limits for such dots for various Ge contents in Sec. III. This knowledge, together with a sound understanding of the dependency of the dot size on the growth parameters, enables the realization of $\mathrm{Si} / \mathrm{Ge}$ heterostructures with effective band gaps as low as 700 $\mathrm{meV}$. $^{5}$

To reduce the rather large size inhomogeneity of the selfassembled dots, which results in a large variation in the quantized energy of the electronic states, we investigated ordering effects in $\mathrm{Si} / \mathrm{Ge}$-dot multilayers with various techniques. The results of these experiments are summarized in Sec. IV. Transmission electron microscopy (TEM) and reciprocal space maps received from $\mathrm{x}$-ray diffraction (XRD)

a) Author to whom correspondence should be addressed; present address: KVG Quartz Crystal Technology GmbH, Gautingerstr. 23, 82131 Stockdorf, Germany; electronic mail: pschittenhelm@vi-kvg.de show not only a strong vertical ordering of the dots, but also a lateral correlation is observed. Atomic force microscopy (AFM) images of the surface dot layer reveal a significantly increased size homogeneity.

Not only basic research aspects have driven the interest in self-assembled Ge dots, but also first attempts have been made, to realize various device concepts based on the large valence band offset and the related small band gap, such as pin-diodes, ${ }^{5,6}$ and $n p n$-transistors for IR detection, or carrier storage devices. ${ }^{7}$ Besides from these optoelectronic applications, we will also present some results on a Si-based tunneling structure, a $p n$-Esaki diode with embedded Ge dots, in Sec. V of this article.

\section{EXPERIMENTAL SETUP}

All samples discussed in this article have been prepared by molecular beam epitaxy in a Riber Siva 32 system, using electron beam evaporators for both $\mathrm{Si}$ and $\mathrm{Ge}$. Details of the growth system and sample preparation have been described elsewhere. ${ }^{8}$

Photoluminescence (PL) measurements were performed at $4 \mathrm{~K}$, using an $\mathrm{Ar}^{+}$laser with a typical power density of $0.1 \mathrm{~W} / \mathrm{cm}^{2}$ for excitation. The signal was detected with a single grating monochromator together with a liquid nitrogen cooled Ge detector in standard lock-in technique.

AFM images were recorded in contact mode with a Topometrix AFM setup operating with standard tips with a radius of approximately $50 \mathrm{~nm}$ in ambient air. The images were automatically analyzed with respect to the areal density of the dots and to the height and diameter of every single dot. A purpose designed software has been developed for this analysis which allowed also for the calculation of the size distribution of the dots. 


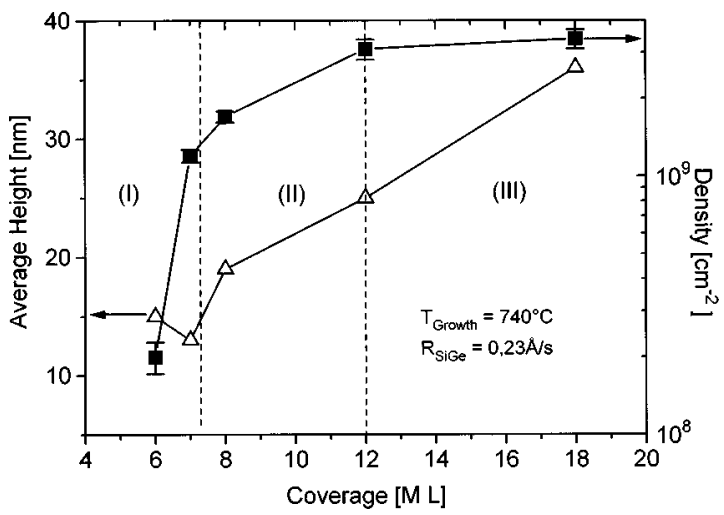

FIG. 1. Average dot height and areal density in dependence of the coverage as received from AFM measurements.

TEM has been accomplished on cross sections of samples thinned by ion milling, using a $400 \mathrm{keV}$ microscope (Jeol JEM-4000EX).

In order to obtain reciprocal space maps of the $\mathrm{Si} / \mathrm{Ge}$-dot supperlattice samples, the $\mathrm{Cu} K \alpha$ line of a Phillips MRD triple-axis diffractometer with a four-crystal Ge (220) monochromator and a double-crystal Ge (220) analyzer has been used to perform XRD measurements.

Photocurrent (PC) spectra were obtained at $200 \mathrm{~K}$, using a tunable broadband source for excitation. Again, a lock-in technique was applied to detect the current. IV characteristics have been analyzed with a Hewlett-Packard parameter analyzer in a temperature controlled four-point setup, that allowed for measurements from 4 to $300 \mathrm{~K}$.

\section{DISLOCATION-FREE DOTS}

In order to be able to utilize self-assembled Ge dots for applications, it is a must to have a thorough understanding of the parameters that influence their formation and growth, and hence determine their size and their physical properties. In order to accomplish this task, we have grown numerous series of samples at different growth temperatures and growth rates, with varying composition and coverage. These parameters determine the surface diffusion length of the Ge adatoms and the amount of builtin strain in the heterostructure, respectively. Their influence on the size and number of the self-assembled dots has been discussed in detail in recent publications. ${ }^{1,6,9}$ Figure 1 gives an overview on the average height and the areal density of an ensemble of $\mathrm{Si}_{0.15} \mathrm{Ge}_{0.85}$ dots grown at a temperature of $740{ }^{\circ} \mathrm{C}$ with a SiGe rate of $0.2 \AA / s$. The data were deduced from AFM images. Three growth regimes, labeled with roman numbers in Fig. 1, can be distinguished. After the onset of dot formation, the average height of the dots remains nearly unchanged, ${ }^{1}$ while their number increases rapidly. At this stage (I), the spatial separation of the dots is larger than the surface diffusion length of the adatoms, therefore, nucleation of additional dots ${ }^{10}$ is more likely than capture of the adatoms by existing ones. With increasing coverage (II), the number of dots starts to saturate, as their average distance approaches the surface diffusion length of the adatoms. At the same time, the dots grow rapidly, as most of the adatoms are now captured by existing dots instead of initiating the nucleation of a new one. A further deposition of SiGe (III) does no longer increase the number of dots, however, their growth continues even faster after the introduction of misfit dislocations in the dots. ${ }^{11,12}$

The critical thickness for the onset of dot formation is readily observable with AFM, and TEM, for example, allows well to resolve, at which critical coverage misfit dislocations start to form within the dots. However, it is not as easy to exactly measure the thickness of the two-dimensional wetting layer which forms in between the dots. While the first two values give the lower and upper limits of the dislocationfree dot regime, the thickness of the wetting layer determines, via the quantization energy in this two-dimensional quantum well, the in-plane band offset and thus the strength of the confinement of the charge carriers in the dots. As the localization of carriers resulting from this confinement is essential for many of the proposed device applications, ${ }^{6}$ the thickness of the two-dimensional wetting layer is also an important characteristic of these self-assembled dots.

In order to address this value, we have grown several series of samples with SiGe layers of different composition and thickness. All SiGe layers were covered with a $90 \mathrm{~nm} \mathrm{Si}$ cap in order to reduce the surface recombination of carriers and to allow for PL investigations. Figure 2(a) displays the PL spectrum of a sample where 5.33 monolayers (ML) of Ge were deposited. Two pairs of PL lines are clearly observable, each consisting of a no-phonon (NP) transition and a transverse optical phonon replica. The pair at the lower energy side of the spectrum stems from the self-assembled dots, while that on the high energy side is attributed to the twodimensional wetting layer. ${ }^{13,14}$ The NP transition energies of the wetting layers of a whole series of samples are shown in Fig. 2(b). For all these samples pure Ge layers have been deposited.

In the case of coverages of $4 \mathrm{ML}$ and less, the measured data are in excellent agreement with the calculated values for a two-dimensional quantum well. These calculated values were obtained taking segregation and interdiffusion during overgrowth of the Ge layer into account, ${ }^{9}$ and are represented by the dashed line in Fig. 2(b). The Ge concentration profile in growth direction received from such a calculation is shown in the inset of Fig. 2(b). For coverages above $4 \mathrm{ML}$ of $\mathrm{Ge}$, a significant blueshift of the measured data with respect to the calculated values is observed. This effect has been explained by a thinning of the wetting layer due to lateral diffusion of Ge into the dots during their formation. ${ }^{14}$ The position of the "kink" in the data curve corresponds well with the critical thickness for the onset of dot formation observed by AFM. For even larger coverages, the NP transition energy reaches a constant value.

From this, the thickness of the remaining two-dimensional wetting layer can be estimated, comparing it with the calculated values. For the samples shown in Fig. 2(b) this results in a wetting layer thickness of approximately 3.5 ML corresponding to $5.6 \AA$, which agrees well with a value of $5 \AA$ 


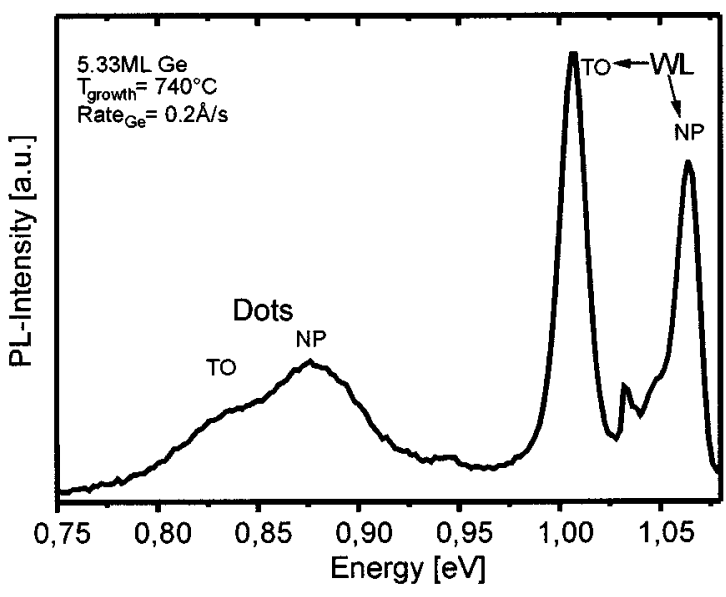

(a)

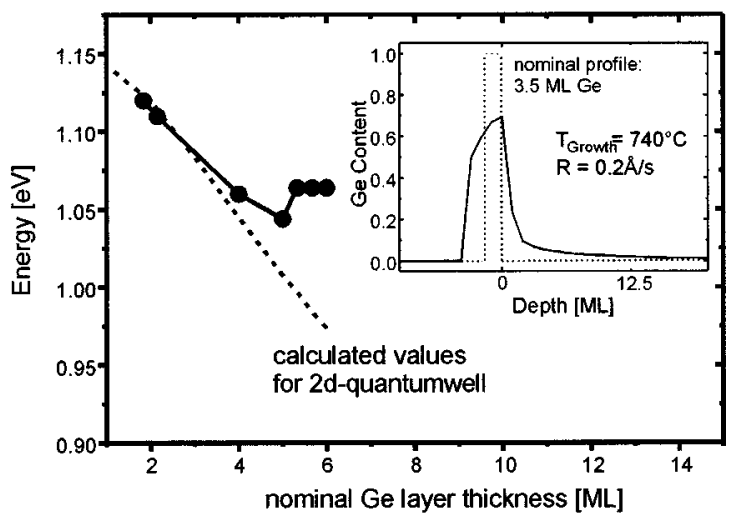

(b)

FIG. 2. (a) PL spectrum of a $5.33 \mathrm{ML}$ Ge layer capped by $90 \mathrm{~nm}$ of Si. (b) NP-transition energies of the wetting layer PL for different Ge coverages. The dashed line represents calculated values for a two-dimensional quantum well according to Ref. 9. The inset shows the calculated Ge concentration profile of the wetting layer in growth direction.

received from XRD measurements. ${ }^{15}$ The same investigation has been repeated on several series of samples with SiGe alloys of different composition, all of them grown at $740{ }^{\circ} \mathrm{C}$ at a Ge rate of $0.2 \AA /$ s. Figure 3(a) gives a compilation of the results of these experiments: the critical thickness for the onset of dot formation $\left(h_{c, \text { dot }}\right)$ as received from AFM and PL measurements, the critical coverage for the introduction of misfit dislocations $\left(h_{c \text {,diss }}\right)$ as received from TEM, and the thickness of the wetting layer $\left(h_{\mathrm{WL}}\right)$ are plotted in dependence of the Ge content of the SiGe alloy.

In Fig. 3(b) the measured values for $h_{c \text {,dot }}$ and $h_{c, \text { diss }}$ are compared with the Matthews-Blakeslee critical thickness for the relaxation of two-dimensional layers via misfit dislocations, ${ }^{16}$ represented by the dashed line. For Ge contents below $x=0.25$, a direct transition from a twodimensional strained layer to a dislocated layer is expected. ${ }^{17}$ For higher Ge contents, there should be an intermediate regime of dislocation free dots, with $h_{c \text {,dot }}$ and $h_{c \text {,diss }}$ as lower and upper limits, respectively. The solid lines in Fig. 3(b) are simple linear interpolations and are only meant to serve as a
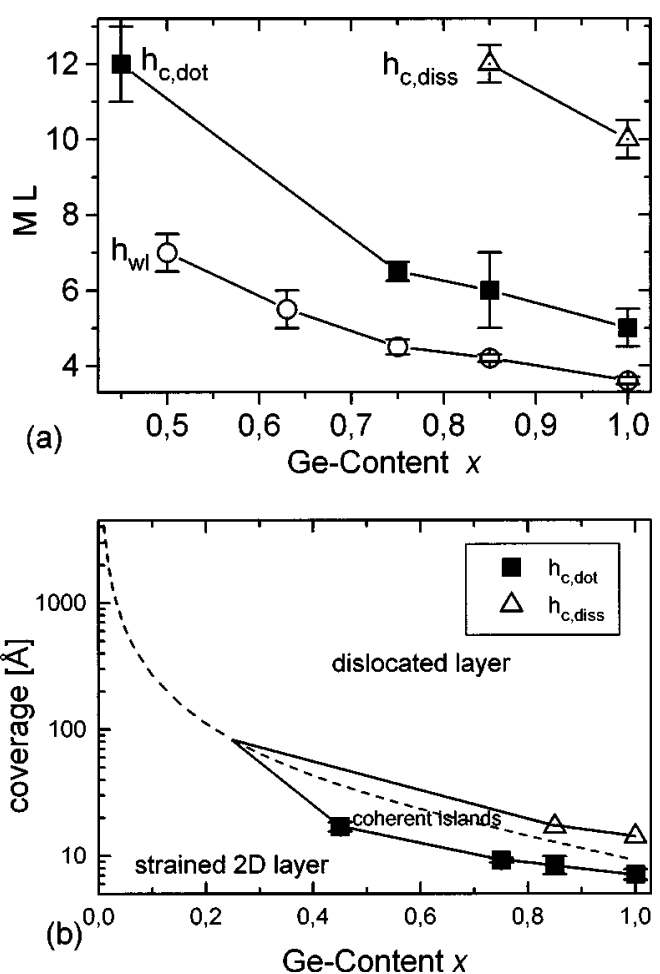

FIG. 3. (a) Characteristic values for Ge layers grown at $740{ }^{\circ} \mathrm{C}$ with a rate of $0.2 \AA / \mathrm{s}$ : onset of dot formation $\left(h_{c, \mathrm{dot}}\right)$, thickness of the wetting layer $\left(h_{\mathrm{WL}}\right)$, and introduction of misfit dislocations $\left(h_{c, \text { diss }}\right)$. (b) Overview on the different growth modes for SiGe alloys at a growth temperature of $740{ }^{\circ} \mathrm{C}$. The dashed curve corresponds to the Matthews-Blakeslee critical thickness.

guide to the eye. However, Fig. 3(b) reveals clearly, that the coverage $h_{c \text {,diss }}$ is well above the Matthews-Blakeslee critical thickness, confirming the expected partial elastic relaxation of strain due to the formation of self-assembled dots. It should be remembered, that the height of the dots is even larger, in the order of 5-8 $\mathrm{nm}$ for the samples discussed. ${ }^{1,6}$ These results clearly demonstrate, that the critical thickness limitation in SiGe heterostructures may be circumvented to a significant extent by the use of self-assembled dots.

\section{ORDERING}

This enlarged critical thickness for the formation of misfit dislocations opens up the road to several novel device concepts, some of which will be discussed later. However, there is a significant drawback in the use of self-assembled dots: their sizes are mostly rather inhomogeneous, resulting in a wide spread of the electronic states of an dot ensemble, a fact that is for example reflected by the broad linewidth of the dot related PL in Fig. 2(a). Various concepts have been discussed in literature to obtain a more homogeneous size distribution, as for example the careful choice of appropriate growth conditions ${ }^{1}$ or the growth on structured ${ }^{18,19}$ or tilted surfaces. ${ }^{20}$

In this article, we focus on the utilization of self-ordering effects to achieve an enhanced size homogeneity and a regular spatial arrangement of the dots in three dimensions. Tersoff $e t a l$. have predicted this effect and have presented first 


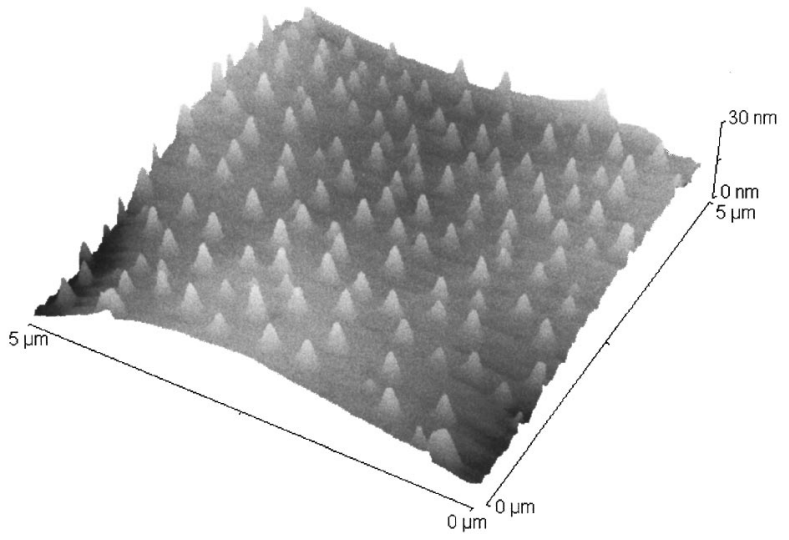

FIG. 4. AFM image of the topmost Ge-dot layer of a 19 period Si/Ge-dot superlattice.

evidence for $\mathrm{Si} / \mathrm{SiGe}$ superlattice structures. ${ }^{21}$ In order to study this phenomenon in more detail, we grew a series of superlattice samples, each consitisting of 19 periods of $d \mathrm{Si} / h \mathrm{Ge}$ with $10 \mathrm{~nm} \leqslant d \leqslant 40 \mathrm{~nm}$ and $5 \mathrm{ML} \leqslant h \leqslant 6 \mathrm{ML}$. All samples were grown at a temperature of $670{ }^{\circ} \mathrm{C}$ with a Ge rate of $0.075 \AA / s$. The topmost Ge layer of all samples remained uncapped to allow for AFM investigations.

Figure 4 shows the AFM image of the topmost layer of a $30 \mathrm{~nm} \mathrm{Si} / 5.5 \mathrm{ML}$ Ge superlattice. The analysis of the height distribution of the dots in the superlattice samples reveals a significantly reduced size variation as compared to a single layer sample. While for a coverage of $5 \mathrm{ML}$, the size variation of the dots in the superlattice sample of $\pm 6 \%$ is comparable to that in a single layer, the value of $\pm 8 \%$ for a $6 \mathrm{ML}$ superlattice sample is much smaller in the case of a single layer, where the size variation amounts to $\pm 28 \%{ }^{1}$ Consequently, these self-ordering effects may indeed enable the growth of homogeneously sized dots. Figure 5(a) displays a cross-sectional TEM image of the $40 \mathrm{~nm} \mathrm{Si} / 5.5 \mathrm{ML}$ Ge superlattice. A nearly perfect vertical correlation of the dots is cleary observable, that also influences the size of the dots. For all samples, the dots in the bottommost layer have a diameter of approximately $150 \mathrm{~nm}$ and a height of $4.5 \mathrm{~nm}$. However, the development of the dimensions of the dots in the subsequent layers is different for samples with a varying thickness $d$ of the Si layers. Figure 5(b) shows the diameter and height of the dots in the 18th layer in dependence of the Si spacer thickness $d$. It can clearly be seen, that both values decrease with increasing values of $d$. The same dependence is observed for the dots in the 19th, uncapped period. This behavior is not yet understood, and will have to be the subject of future investigations. However, the fact itself is confirmed by XRD measurements, that reveal a reduced vertical correlation length for the samples with thinner $\mathrm{Si}$ spacers, which can be understood in terms of a larger gradient in dot size occuring in these samples. ${ }^{22}$

The same sample, that is shown in Fig. 5(a), has also been investigated by XRD, using the reciprocal space mapping technique. In Fig. 6(a), the measured reciprocal space map around the (113) reciprocal lattice point is depicted. The sub-
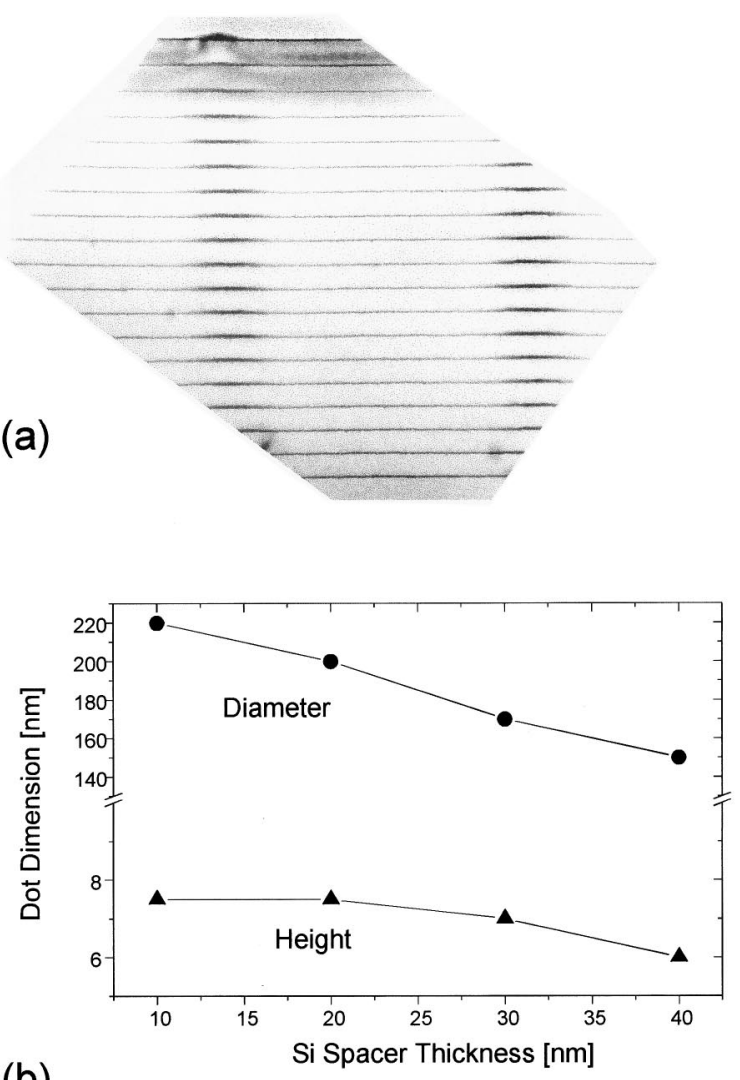

(b)

FIG. 5. (a) TEM cross section of a 19 period $40 \mathrm{~nm} \mathrm{Si} / 5.5 \mathrm{ML}$ Ge superlatice. The vertical correlation of the dots is clearly observable. (b) Diameter and height of dots in the topmost capped dot layer in dependence of the Si spacer thickness $d$.

strate peak $(S)$ and the coherent superlattice peaks $\left(S L_{0, \pm 1}\right)$ of the vertical superlattice are clearly observable. The width of the superlattice peaks is comparable to that of the substrate peak, clearly indicating the high structural quality of the layer sequence. The feature labeled (A) represents the analyzer streak, an XRD artefact. Besides the peaks of the vertical superlattice, additional maxima of the scattered intensity occur in the reciprocal space map $\left(D_{0, \pm 1}\right)$. In order to clarify the nature of these additional maxima, the diffuse scattering pattern of an array of dots has been calculated, ${ }^{22}$ assuming an arrangement of dots of identical size in a disordered square lattice with axes parallel to the [100] and [010] direction. The results of these calculations are shown in Fig. 6(b). The calculated reciprocal space map clearly corresponds to the measured features labeled $\left(D_{0, \pm 1}\right)$. Consequently, these can be attributed to a diffuse scattering from the dots. A more detailed analysis of the reciprocal space maps reveals, that the lateral correlation of the dots is only of a short range type, as the variation of the mean dot distance of approximately $520 \mathrm{~nm}$ amounts to $180 \mathrm{~nm} .^{22}$

\section{DEVICE CONCEPTS}

In order to demonstrate the applicability of self-assembled Ge dots in device structures, we investigate two different 

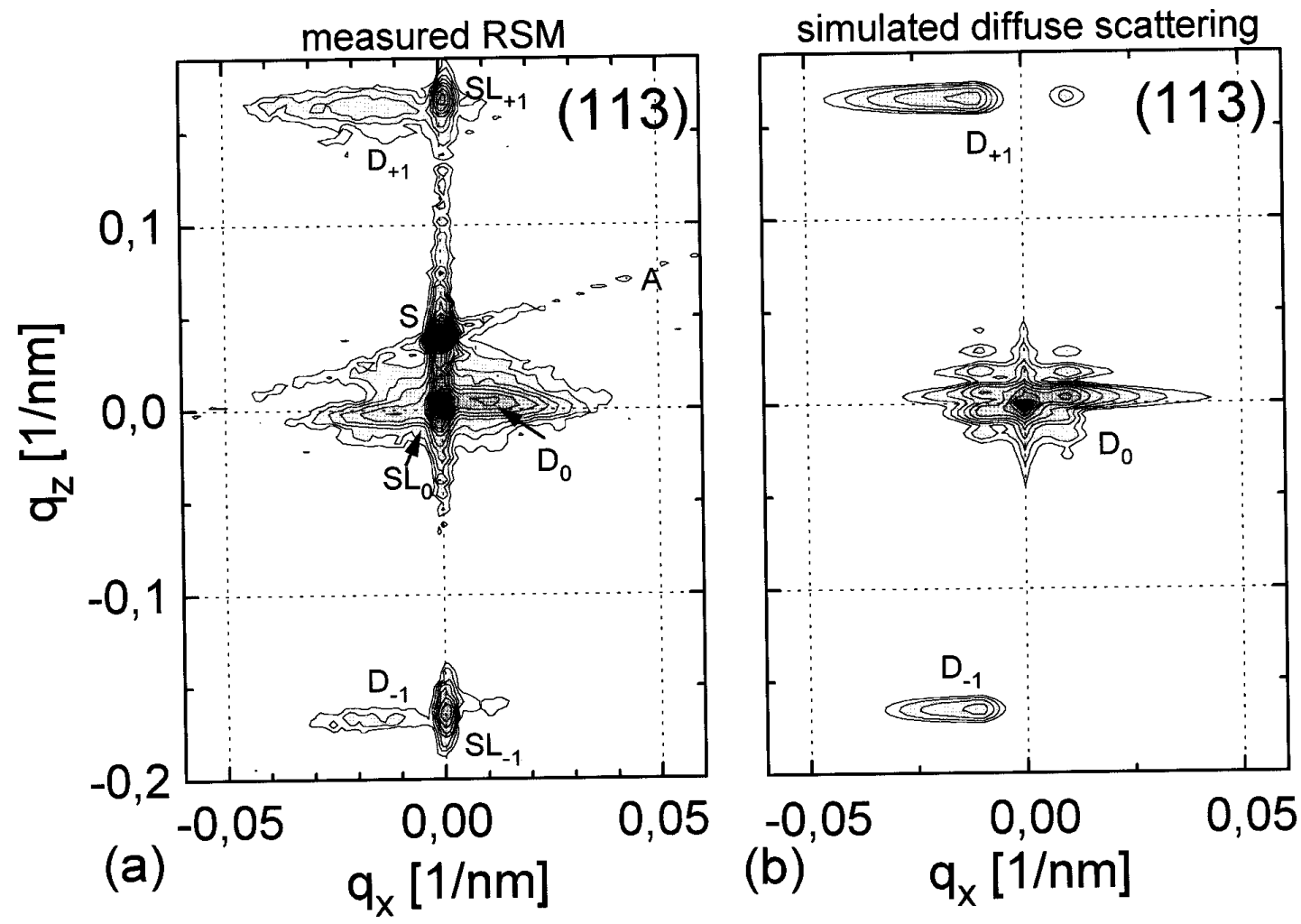

FIG. 6. (a) Measured XRD reciprocal space map of a 19 period $40 \mathrm{~nm} \mathrm{Si} / 5.5 \mathrm{ML}$ Ge superlattice. (b) Calculated diffuse scattering contribution of the array of self-assembled dots of the same sample to the reciprocal space map.

concepts: the enhancement of infrared detection in pin and npn structures due to the introduction of Ge dots with small band gaps as absorbing layers, and the realization of Sibased tunneling structures using Esaki-type $p n$ structures.

The experiments on pin-diode structures did not lead to the expected increase in infrared absorbtion as compared to pseudomorphic SiGe quantum wells and are discussed elsewhere. ${ }^{5}$ However, in a $n-\mathrm{Si} / p-\mathrm{Ge} / n$-Si heterostructure, a band edge modulation as sketched in Fig. 7(a) should result. This structure will lead to a localization of the photoexited holes in the $p$-type base formed by the Ge dots, while the built in field of the base-collector junction drives the photogenerated electrons towards the collector. The holes confined in the base lead to an electrostatic reduction of the doping induced conduction-band modulation in the base, resulting in an exponential increase of the thermionic electron current. This mechanism provides an internal amplification of the photocurrent, that should result in a significantly enhanced photosensitivity. To investigate this effect, we performed PC spectroscopy experiments on samples whose base region consisted of three layers of $12 \mathrm{ML} p$-doped Ge separated by $6 \mathrm{~nm}$ of nominally undoped Si. This base region was embedded in $n$-doped Si emitter and collector regions. The whole layer sequence was grown on a $n$-type $\mathrm{Si}$ substrate to allow for a back contact without mesa etching. The front contact was carried out in a windowlike form to enable illumination. For comparison, a reference structure was grown, in which the dot layers were replaced by $\mathrm{Si}_{0.6} \mathrm{Ge}_{0.4}$ quantum wells with a thickness of $30 \AA$.
The PC spectra of both samples are shown in Fig. 7(b). For the sample with the dot layers, not only the onset of the photocurrent is shifted to smaller energies, indicating a smaller band gap, but also the absolute value of the PC is about one order of magnitude larger than in the reference sample. The inset of Fig. 7(b) contains an $I-V$ curve of the dot layer sample without illumination under floating base condition, confirming the $n p n$ characteristic of the sample structure. For the technologically important wavelength of $1.33 \mu \mathrm{m}$, a maximum external quantum efficiency of $4 \%$ was measured in normal incidence geometry.

Another concept which exploits the small band gaps of self-assembled Ge dots is shown in Fig. 8(a). If a Ge dot layer is embedded between highly $p$ - and $n$-doped Si layers, Esaki tunneling from the $n$-conduction band through the dots to the $p$-valence band may occur at an appropriate bias. ${ }^{23}$ As the tunneling probability increases strongly with decreasing band gap, the tunneling current in such a structure is expected to be significantly higher than in a Si reference structure. This should allow to realize Si-based tunneling structures for use in high frequency applications, for example.

The $I-V$ curves of two such tunneling diodes measured at $4 \mathrm{~K}$ are shown in Fig. 7(b). Both structures were grown on a highly $p$-doped Si-substrate and consist of a $6 \times 10^{19} \mathrm{~cm}^{-3}$ boron-doped $\mathrm{Si}$ buffer layer and a $9 \times 10^{19} \mathrm{~cm}^{-3}$ phosphorous-doped $\mathrm{Si}$ cap layer, but only in one structure a Ge-dot layer was introduced. Both samples display pronounced Zener tunneling when biased in reverse direction. ${ }^{24}$ However, as expected, the current through the diode contain- 


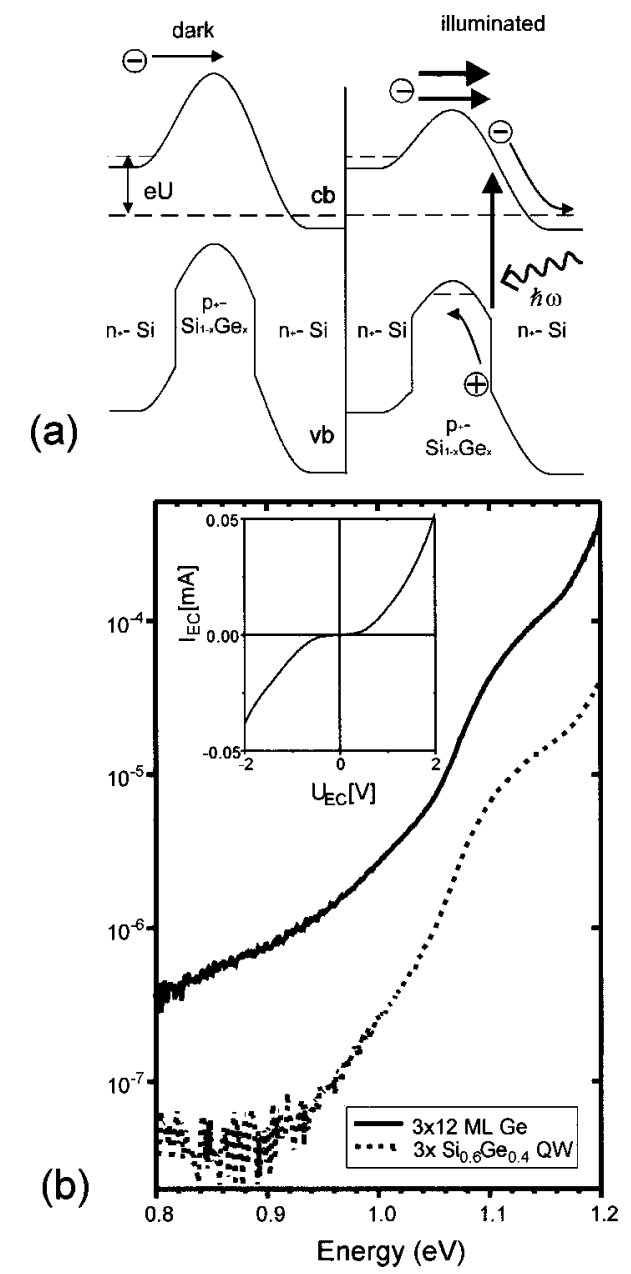

FIG. 7. (a) Band edge modulation of a $n p n$ structure with a Ge dot layer in the $p$-base region, with and without illumination. (b) Photoresponse of $n p n$ structures with Ge-dot layers embedded in the $p$ region, compared to $n p n$ structures with two-dimensional $\mathrm{SiGe}$ quantum wells in the $p$ region. Inset: $I-V$ characteristic with floating base.

ing the Ge dots is nearly three orders of magnitude higher. The same statement applies for forward bias, although a negative differential resistance is only observed in the case of the Si reference structure. Several reasons may account for the absence of a negative differential resistance in the case of the diode with the Ge dot layer. Different dot sizes, for example, resulting in a variation of the effective band gaps, would lead to a peak of the tunneling current through the respective dots at different bias voltages, consequently producing a broadening of the Esaki peak. ${ }^{23}$ Another explanation could be found in an increased excess current due to structural imperfections of the dot layer. Although these questions are still to be answered, the existing data demonstrate, that it is possible to grow Si-based tunneling structures by MBE, and they give strong evidence of an effectively enhanced tunneling current due to the introduction of a layer of self-assembled Ge dots.

\section{CONCLUSIONS}

In conclusion, we have presented upper and lower coverage limits for the dislocation-free $\mathrm{SiGe}$ dot regime at a
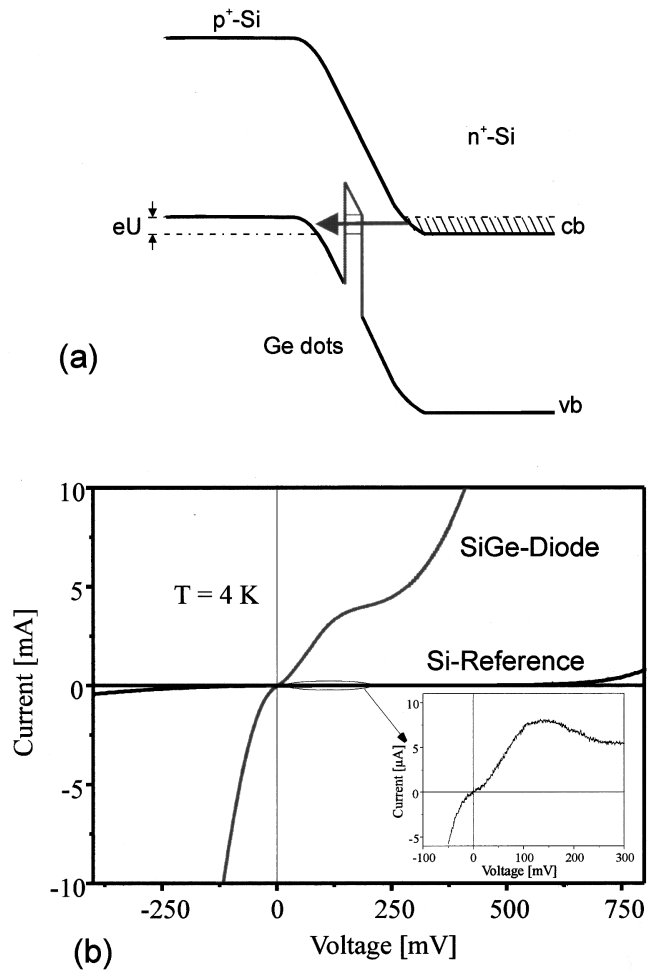

FIG. 8. (a) Band edge diagram of an Esaki-type $p n$-tunneling diode with embedded Ge dots. (b) $I-V$ characteristics of MBE-grown $p n$-tunneling diodes with and without Ge dots.

growth temperature of $740{ }^{\circ} \mathrm{C}$ for various Ge contents. Together with previously published results on the dependence of the dot size on the growth parameters and with the thicknesses of the two-dimensional wetting layers presented in this article, these results should allow for the customized engineering of the band edge modulation of the selfassembled dot layers. We have also shown, that $\mathrm{Si} / \mathrm{Ge}$-dot superlattices provide a means to produce ensembles of dots of homogeneous size and rather regular spacings. Furthermore we have demonstrated an infrared photodetector based on Ge dots with high external efficiency in normal incidence geometry, and first evidence for an enhanced Esaki tunneling in $p n$ diodes with embedded Ge dots. In spite of some unanswered questions, we hope that our findings will stimulate further work on this promising field.

\section{ACKNOWLEDGMENTS}

This work was in part supported by BMBF, Bonn, under contract 01 M 2953 B2, by the Bayerische Forschungsstiftung via FOROPTO, and by BMWF, Vienna, under the "Nanostrukturierung"' project. The authors gratefully acknowledge technical assistance by $\mathrm{H}$. Riedl.

${ }^{1}$ P. Schittenhelm, G. Abstreiter, A. Darhuber, G. Bauer, P. Werner, and A. Kosogov, Thin Solid Films 294, 291 (1997).

${ }^{2}$ S. Fafard, R. Leon, D. Leonard, J. L. Merz, and P. M. Petroff, Phys. Rev. B 50, 8086 (1994). 
${ }^{3}$ D. C. Houghton, Appl. Phys. Lett. 57, 14 (1990).

${ }^{4}$ D. J. Eaglesham and M. Cerullo, Phys. Rev. Lett. 64, 1943 (1990).

${ }^{5}$ P. Schittenhelm, E. Silveira, C. Engel, G. Abstreiter, A. O. Kosogov, and

P. Werner (to be published).

${ }^{6}$ G. Abstreiter, P. Schittenhelm, C. Engel, E. Silveira, A. Zrenner, D. Meertens, and W. Jäger, Semicond. Sci. Technol. 11, 1521 (1996).

${ }^{7} \mathrm{C}$. Engel, Si/SiGe-basierende Phototransistoren (1997).

${ }^{8}$ J. Brunner, J. Nützel, M. Gail, U. Menczigar, and G. Abstreiter, J. Vac. Sci. Technol. B 10, 319 (1995).

${ }^{9}$ P. Schittenhelm, M. Gail, and G. Abstreiter, J. Cryst. Growth 157, 260 (1995).

${ }^{10}$ J. A. Venables, J. Vac. Sci. Technol. B 4, 870 (1986).

${ }^{11}$ M. Krishnamurthy, J. S. Drucker, and J. A. Venables, J. Appl. Phys. 69, 6461 (1991).

${ }^{12}$ D. Leonard, K. Pond, and P. M. Petroff, Phys. Rev. B 50, 11687 (1994).

${ }^{13}$ H. Sunamura, N. Usami, Y. Shiraki, and S. Fukatsu, Appl. Phys. Lett. 66, 3024 (1995).
${ }^{14}$ P. Schittenhelm, M. Gail, J. Brunner, J. F. Nützel, and G. Abstreiter, Appl. Phys. Lett. 67, 1292 (1995).

${ }^{15}$ A. A. Darhuber, V. Holy, J. Stangl, G. Bauer, P. Schittenhelm, and G. Abstreiter, Proc. Mater. Res. Soc. 448, 153 (1997).

${ }^{16}$ J. W. Matthews and A. E. Blakeslee, J. Cryst. Growth 27, 118 (1974).

${ }^{17}$ J. Tersoff and F. K. LeGoues, Phys. Rev. Lett. 72, 3570 (1994).

${ }^{18}$ W. Seifert, N. Carlsson, A. Petersson, L. E. Wernersson, and L. Samuelson, Appl. Phys. Lett. 68, 1684 (1996).

${ }^{19}$ T. I. Kamins and R. S. Williams, Appl. Phys. Lett. 71, 1201 (1997).

${ }^{20}$ J. Zhu and G. Abstreiter (unpublished).

${ }^{21}$ J. Tersoff, C. Teichert, and M. G. Lagally, Phys. Rev. Lett. 76, 1675 (1996).

${ }^{22}$ A. A. Darhuber, P. Schittenhelm, V. Holy, J. Stangl, G. Bauer, and G. Abstreiter, Phys. Rev. B 55, 15652 (1997), and references therein.

${ }^{23}$ L. Esaki, Phys. Rev. 106, 603 (1958).

${ }^{24}$ C. Zener, Proc. R. Soc. London, Ser. A 145, 523 (1934). 